\title{
Fluctuation-driven rhythmogenesis in an excitatory neuronal network with slow adaptation
}

\author{
William H. Nesse • Alla Borisyuk • Paul C. Bressloff
}

Published online: 7 October 2008

(C) Springer Science + Business Media, LLC 2008

\section{Erratum to: J Comput Neurosci}

\section{DOI 10.1007/s10827-008-0081-y}

The publisher regrets that a reference was incorrectly printed for the article, "Fluctuation-driven rhythmogenesis in an excitatory neuronal network with slow adaptation," by William H. Nesse, Alla Borisyuk and Paul C. Bressloff, which published in Journal of Computational Neuroscience 25:2, 317-333. The updated reference is below:

\section{References}

Vladimirski, B. B., Tabak, J., O’Donovan, M. J., \& Rinzel, J. (2008). Episodic activity in a heterogenious excitatory network, from spiking neurons to mean field. Journal of Computational Neuroscience, 25, 39-63.

The online version of the original article can be found at http://dx.doi. org/10.1007/s10827-008-0081-y.

W. H. Nesse • A. Borisyuk • P. C. Bressloff $(\bowtie)$

Department of Mathematics, University of Utah,

Salt Lake City, UT 84112, USA

e-mail: bressloff@math.utah.edu 